\title{
Beyond learner autonomy: A dynamic systems view of the informal learning of English in virtual online communities
}

\author{
Geoffrey Sockett* \& Denyze Toffoli \\ DLADL, Université de Strasbourg, 22 rue René Descartes 67084 Strasbourg, France
}

\begin{abstract}
This paper discusses the informal learning of English by non-native speakers with particular reference to the role of virtual communities. A model of informal language learning is presented and related to current areas of interest in the literature such as task-based learning and dynamic systems theory. This model is used to question the relevance of the learner autonomy model, which has been a cornerstone of language learning policy in Europe for the past 30 years. A research project is discussed, with particular attention to the relevant research methodologies in this field, investigating how non-specialist language learners use the Internet in their spare time to read and listen to English, and also communicate in English, notably in online communities through social networking websites.
\end{abstract}

(C) 2012 Published by Elsevier B.V. Selection and/or peer-review under responsibility of EUROCALL2010 Scientific Committee Open access under CC BY-NC-ND license.

Keywords: informal learning; learner autonomy; dynamic systems theory; virtual communities

\section{Introduction}

Our current understanding of the informal learning of English in France today (Sockett, 2010), actionoriented learning, associative-cognitive learning models (Ellis, 2007) and dynamic systems theory (Van Geert, 2008), may render the learner autonomy model of the 1980s less relevant than it once was as a way of describing and prescribing the learning and teaching of English in France. For example, whereas the learner autonomy model seeks to encourage the learner to take charge of his or her learning in a resource centre, the current availability of online media and communication tools means that the English learner is already involved in language use, and is better described in the terms of action-oriented approaches as a user of the language and a social agent.

\footnotetext{
* Geoffrey Sockett. Tel.: +33 368856585

gsockett@unistra.fr
} 
Informal learning does not happen in the classroom or according to a fixed timetable, it is not the product of simply creating a more convivial atmosphere in the classroom, and indeed as an impromptu activity it may not be planned by the learner (Cross, 2007). As such it has links with other paradigms such as incidental learning (Rieder, 2003). The recent Study on the Impact of ICT and New Media on Language Learning (Stevens, 2010) supports this view.

The impromptu nature of informal learning is also an indication that it is emergent, taking place in a complex dynamic system. Among the characteristics of dynamic systems presented by Van Geert (2008), four seem to be particularly relevant to the study of informal language learning: (a) the importance of initial conditions which are no longer uniform for all learners; (b) the study of attractor and repeller states in a system, showing how some learner strategies can at first help before later becoming a hindrance; (c) the possibility of co-adaptation of elements in the system giving rise to unexpected learning behaviours emerging from interactions between the large number of tools and contexts available to the learner; and finally (d) the non-linear nature of complex dynamic systems which leads to phase transitions, such as jumps in degrees of fluency or comprehension unrelated to changes the quantity of exposure to the language.

When learners participate in virtual communities with other English users, opportunities arise to use the language in real contexts, such as work or leisure related settings. Although watching downloaded or streamed media in the original language involves little or no two-way interaction with other users of English (our research suggests that viewing habits are rarely the subject of Facebook interactions, for example), such activities also bring learners into prolonged contact with a shared language and set of values and references which often characterise belonging to a community.

An initial study into informal language learning was carried out in 2009. 225 students at the University of Strasbourg were surveyed regarding their contact with English online in their free time (Sockett, 2010; Toffoli \& Sockett, 2010). While two of the sample reported having no contact with English in their free time at all, $60 \%$ of the respondents reported regularly downloading or streaming films and television series in English, and some 30\% corresponded regularly with other English users on social the networking website Facebook. Other activities involving English included visiting English language websites, listening to music with English lyrics online, and sending e-mails to friends.

\section{Method}

The 2009 study provides a good basic understanding of these phenomena among students in France, but gives few details about the precise times and contents involved, and how students' behaviour changes over time. It was therefore decided to design an eight-week diary study in which a small number of students from the first sample would report on each occurrence of online English use in their spare time, indicating the websites and times involved and recording any insights into their use of the language. At the end of the study, the students were also interviewed to clarify some entries in the completed diaries. The study sought to answer three main questions: (1) Do stable contacts with English persist over a long period, allowing these students to be correctly described as English users? (2) Can these English users be seen to be functioning in virtual communities? (3) What interactions between components in their complex personal learning environments emerge from this language use?

The choice of methodology for this work was influenced by Larsen-Freeman and Cameron (2008) who suggest, for example, that qualitative longitudinal studies of a few learners are more likely to yield insights into the dynamics of these complex systems. 


\section{Results}

The results of this research were broadly in line with the first study, while providing further insights into the research hypotheses mentioned earlier. Students reported downloading or streaming popular English and American television series, and using Facebook to keep in touch with other English users known personally to them.

Results which were not provided by the 2009 study included insights into the way the respondents listen to music online, visit websites, and learn vocabulary. Four of the six students reported using ondemand music services such as Deezer rather than streaming from the website of a radio station. These students also mentioned examples of concurrent use of lyrics websites such as lacoccinelle.net. The web surfing practices of the students involved frequent use of the same websites, often those relating to their major field of study. In addition to social networking sites, news sites such as bbc.co.uk were visited regularly, and video content was generally streamed or downloaded from the same websites. While respondents often left blank the column in the diary reserved for comments on the language, the most frequent examples referred to learning new vocabulary items from the resources being used.

It may be useful to look in detail at results from one student as an example. AH spent 37 hours using English online over the seven weeks she was involved in the study, which is close to the average for the group. This consisted of 34 different occasions on which she went online, almost exclusively during the evening and at weekends. During this time she used Facebook 16 times to interact with friends she had met on holiday. She also watched downloaded or streamed TV series on eight occasions for periods of between 45 minutes and two hours. She listened to music on Deezer three times and used lacoccinelle.net on each occasion to look up song lyrics. Her use of websites was mainly work related, using English language websites six times. She reported incidental vocabulary acquisition from the television series and reading song lyrics for meaning.

\section{Discussion}

While the impact of online media viewing and the use of Facebook have already been discussed (Sockett, 2010), the appearance of data for on-demand music services was an unexpected aspect of the study. Use of the Deezer service is widespread in France and our research indicates that the affordances of such systems, particularly the ability to choose, play and pause songs, leads to a more active approach to listening in some cases. Thus learners have time to use websites containing the lyrics of songs they are listening to on Deezer, which would be difficult were they listening to live radio feeds. The observation of synchronous use of music on demand and lyrics websites, by which some learners have in a way created a function in their personal learning environments facilitating learning from song lyrics, may indeed be an example of the co-adaptation of system and context suggested by Van Geert (2008) as a property of the dynamics of a complex system.

The language learning observable from this research seems mostly to relate to vocabulary acquisition. Like other English users, the learners in this study acquire vocabulary incidentally in the course of other activities. While noticing is taking place (Skehan, 1998), acquisition in this context relies on high frequency, high context exposure to salient examples. This view of language learning as the acquisition of chunks or bundles of language fits in well with connectionist views of learning favoured by researchers in the field of complex systems today (e.g. Ellis, 2007). 


\section{Conclusions}

Pedagogical applications of this research should involve consideration of how best to take account of these informal learning practices in formal instruction. Much of the current research into virtual communities and foreign language learning seeks merely to bring social networking tools into the classroom rather than acknowledging that learning is more likely to take place in virtual communities outside the classroom where available time, existing virtual communities and intrinsic motivation are already in place. Many of the same skills required to participate in exchanges on Facebook (deciding which comments to respond to, referring to other participants, etc.) are useful in contexts such as thematic forums, where identities are less obvious and the subject matter may be of a less personal nature. It is therefore possible that forums would constitute a better classroom activity than social networks, while still helping learners to develop relevant communication skills.

\section{References}

Cross, J. (2007). Informal learning. San Francisco, CA: Pfeiffer.

Ellis, N. (2007). The associative cognitive creed. In W. Van Patten \& J. Williams (Eds.), Theories in second language acquisition. Mahwah, NJ: Lawrence Erlbaum Associates.

Larsen-Freeman, D., \& Cameron, L. (2008). Complex systems and applied linguistics. Oxford: Oxford University Press.

Rieder, A. (2003). Implicit and explicit learning in incidental vocabulary acquisition. Views, 12(2), 24-39.

Skehan, P. (1998). A cognitive approach to language learning. Cambridge: Cambridge University Press.

Sockett, G. (2010). Les processus cognitifs de résolution de problèmes pour l'apprentissage des langues dans des environnements multimédia: Apprentissage informel et réseaux sociaux. In Actes du colloque ACEDLE: Recherches en didactique des langues - Les langues tout au long de la vie. Retrieved from http://evenements.univ-lille3.fr/colloque-acedle2009/pdf/actes-colloque.pdf

Toffoli, D., \& Sockett, G. (2010). How non-specialist students of English practice informal learning using web 2.0 tools. ASp, 58, 125-144.

Stevens, A. (2010). Study on the impact of information and communications technology (ICT) and new media on language learning . European Commission. Retrieved from http://eacea.ec.europa.eu/llp/studies/documents/study_impact_ict_new_media_language_learning/final_report_en.pdf

Van Geert, P. (2008). The dynamic systems approach in the study of L1 and L2 acquisition: An introduction. Modern language Journal, 92(2), 179-199. 